\title{
A vacuum ultraviolet ion source (VUV-IS) for iodide-chemical ionization mass spectrometry: a substitute for radioactive ion sources
}

\author{
Yi Ji ${ }^{1}$, L. Gregory Huey ${ }^{1}$, David J. Tanner ${ }^{1}$, Young Ro Lee ${ }^{1}$, Patrick R. Veres ${ }^{2}$, J. Andrew Neuman ${ }^{2,3}$, Yuhang Wang ${ }^{1}$, \\ and Xinming Wang ${ }^{4}$ \\ ${ }^{1}$ School of Earth and Atmospheric Sciences, Georgia Institute of Technology, Atlanta, Georgia 30332, USA \\ ${ }^{2}$ NOAA Chemical Science Laboratory, Boulder, Colorado 80305, USA \\ ${ }^{3}$ Cooperative Institute for Research in Environmental Sciences, University of Colorado Boulder, \\ Boulder, Colorado 30309, USA \\ ${ }^{4}$ State Key Laboratory of Organic Geochemistry, Guangzhou Institute of Geochemistry, \\ Chinese Academy of Sciences, Guangzhou, 510640, China
}

Correspondence: L. Gregory Huey (greg.huey@eas.gatech.edu)

Received: 16 January 2020 - Discussion started: 3 February 2020

Revised: 6 May 2020 - Accepted: 24 May 2020 - Published: 9 July 2020

\begin{abstract}
A new ion source (IS) utilizing vacuum ultraviolet (VUV) light is developed and characterized for use with iodide-chemical ionization mass spectrometers ( $\mathrm{I}^{-}$-CIMS). The VUV-IS utilizes a compact krypton lamp that emits light at two wavelengths corresponding to energies of $\sim 10.030$ and $10.641 \mathrm{eV}$. The VUV light photoionizes either methyl iodide (ionization potential, IP $=9.54 \pm 0.02 \mathrm{eV}$ ) or benzene $(\mathrm{IP}=9.24378 \pm 0.00007 \mathrm{eV})$ to form cations and photoelectrons. The electrons react with methyl iodide to form $\mathrm{I}^{-}$, which serves as the reagent ion for the CIMS. The VUV-IS is characterized by measuring the sensitivity of a quadrupole CIMS (Q-CIMS) to formic acid, molecular chlorine, and nitryl chloride under a variety of flow and pressure conditions. The sensitivity of the Q-CIMS, with the VUV-IS, reached up to $\sim 700 \mathrm{Hzptv}^{-1}$, with detection limits of less than $1 \mathrm{pptv}$ for a $1 \mathrm{~min}$ integration period. The reliability of the Q-CIMS with a VUV-IS is demonstrated with data from a month-long ground-based field campaign. The VUV-IS is further tested by operation on a high-resolution time-of-flight CIMS (TOFCIMS). Sensitivities greater than $25 \mathrm{~Hz} \mathrm{pptv}^{-1}$ were obtained for formic acid and molecular chlorine, which were similar to that obtained with a radioactive source. In addition, the mass spectra from sampling ambient air was cleaner with the VUV-IS on the TOF-CIMS compared to measurements using a radioactive source. These results demonstrate that the VUV lamp is a viable substitute for radioactive ion sources
\end{abstract}

on $\mathrm{I}^{-}$-CIMS systems for most applications. In addition, initial tests demonstrate that the VUV-IS can be extended to other reagent ions by the use of VUV absorbers with low IPs to serve as a source of photoelectrons for high IP electron attachers, such as $\mathrm{SF}_{6}^{-}$.

\section{Introduction}

Chemical ionization mass spectrometry (CIMS) has been widely used as a powerful tool to measure various atmospheric compounds with high sensitivity and fast time response. CIMS measurements are based on selective ionization of compounds in air by reagent ions via ion molecule reactions. CIMS using the iodide anion $\left(\mathrm{I}^{-}\right)$and its water clusters as reagent ions $\left(\mathrm{I}^{-}\right.$-CIMS) has been widely used in the measurements of many atmospheric trace gases, e.g., organic and inorganic acids (hydrogen chloride, $\mathrm{HCl}$; nitric acid, $\mathrm{HNO}_{3}$; formic acid, $\mathrm{HCOOH}$; etc.), halogens (bromine oxide, $\mathrm{BrO}$; nitryl chloride, $\mathrm{ClNO}_{2}$; etc.), and peroxycarboxylic nitric anhydrides (PANs) (Slusher et al., 2004; Huey, 2007; Phillips et al., 2013; Lee et al., 2014; Liao et al., 2014; Neuman et al., 2016; Liu et al., 2017; Priestley et al., 2018; Bertram et al., 2011; Thornton et al., 2010; Osthoff et al., 2008). 
Typically, $\mathrm{I}^{-}$-CIMS systems use a radioactive isotope, usually ${ }^{210} \mathrm{Po}$, as an ion source. ${ }^{210} \mathrm{Po}$ emits $\alpha$ particles (with an energy of $\sim 5 \mathrm{MeV}$ ) that directly ionize the carrier gas in the ion source to produce secondary electrons. The secondary electrons are thermalized by collisions and react with methyl iodide $\left(\mathrm{CH}_{3} \mathrm{I}\right)$ to form $\mathrm{I}^{-}$by dissociative electron attachment. The use of radioactive ion sources with the $\mathrm{I}^{-}$-CIMS system is well established and has several important advantages. For example, radioactive sources are exceedingly reliable and easy to use, as they require no external power. Radioactive sources often produce relatively clean mass spectra with few interfering masses. However, radioactive sources have several disadvantages as well. ${ }^{210} \mathrm{Po}$ is toxic and is highly regulated, which often makes it difficult to transport, store, and use in remote locations. We have recently developed a lower activity ${ }^{210} \mathrm{Po}$ ion source that is subject to fewer regulatory restrictions (Lee et al., 2020). However, there remain applications where the use of any radioactivity is very difficult or prohibited. A more subtle disadvantage is that radioactive ion sources emit continuously, which can lead to the build-up of interfering species. For these reasons, it is desirable to find a nonradioactive alternative to efficiently generate $\mathrm{I}^{-}$and other reagent ions. Electrical discharges and $\mathrm{x}-$ ray ion sources have been used as ion sources in atmospheric pressure chemical ionization mass spectrometers (AP-CIMS) (Jost et al., 2003; Skalny et al., 2007; Kurten et al., 2011; Wang et al., 2017). However, they have not been commonly employed with $\mathrm{I}^{-}$-CIMS systems perhaps due to limited sensitivity and the generation of interfering ions. Recently Eger et al. (2019) developed a promising ion source using a radio frequency (RF) discharge on an $\mathrm{I}^{-}$-CIMS system, providing another alternative to radioactive sources albeit with lower signal levels. However, the RF source also generated high levels of other ions such as dicyanoiodate anion $\mathrm{I}(\mathrm{CN})_{2}^{-}$, which can lead to interference but also provide additional pathways for detecting species such as $\mathrm{SO}_{2}$ and $\mathrm{HCl}$.

In this work, we investigate the use of a small krypton ( $\mathrm{Kr})$ lamp as a substitute for a radioactive ion source on an $\mathrm{I}^{-}$CIMS. Similar lamps have been commonly used in atmospheric pressure photoionization-mass spectrometry (e.g., Kauppila et al., 2017). The vacuum ultraviolet (VUV) light is generated from two emission lines centered at 116.486 (photon energy $=10.641 \mathrm{eV}$ ) and $123.582 \mathrm{~nm}$ (photon energy $=10.030 \mathrm{eV}$ ). $\mathrm{CH}_{3} \mathrm{I}$ has a large absorption cross section $\left(7 \times 10^{-17} \mathrm{~cm}^{2}\right.$ molecule $\left.{ }^{-1}\right)$ at these wavelengths and a relatively low ionization potential $(\mathrm{IP}=9.54 \pm 0.02 \mathrm{eV}$ ) (Holmes and Lossing, 1991; Olney et al., 1998). Absorption of the VUV light by $\mathrm{CH}_{3} \mathrm{I}$ forms cations and relatively low-energy photoelectrons, which can then attach to $\mathrm{CH}_{3} \mathrm{I}$ to form $\mathrm{I}^{-}$. Benzene $\left(\mathrm{C}_{6} \mathrm{H}_{6}\right)$ can also serve as a VUV absorber to produce photoelectrons as it has a larger absorption cross section $\left(4 \times 10^{-17} \mathrm{~cm}^{2}\right.$ molecule $\left.{ }^{-1}\right)$ and an even lower IP $(9.24378 \pm 0.00007 \mathrm{eV})$ (Nemeth et al., 1993; Capalbo et al., 2016). We explore the use of $\mathrm{C}_{6} \mathrm{H}_{6}$ as a source of photoelectrons as we have found that delivering even mod- est quantities of gas-phase $\mathrm{CH}_{3} \mathrm{I}$ to our ion source can be problematic as it has a tendency to polymerize to nonvolatile species in compressed gas cylinders. Tests of $\mathrm{C}_{6} \mathrm{H}_{6}$ as a photoelectron source in this work are performed as it may enhance ion production when used in combination with lower levels of $\mathrm{CH}_{3} \mathrm{I} . \mathrm{C}_{6} \mathrm{H}_{6}$ may also be used as an electron source for use with other electron-attaching compounds with higher IPs, such as $\mathrm{SF}_{6}$, to form reagent ions such as $\mathrm{SF}_{6}^{-}$.

The performance of the vacuum ultraviolet ion source (VUV-IS) was characterized by measuring the sensitivities on a quadrupole CIMS (Q-CIMS) to formic acid, chlorine $\left(\mathrm{Cl}_{2}\right)$, and nitryl chloride $\left(\mathrm{ClNO}_{2}\right)$, under different flow conditions with varying levels of $\mathrm{CH}_{3} \mathrm{I}$. Similar tests were also performed using a flow of both $\mathrm{C}_{6} \mathrm{H}_{6}$ and $\mathrm{CH}_{3} \mathrm{I}$ through the ion source. Potential interferences due to the VUV light interacting with air or surfaces are investigated by comparing ambient mass spectra obtained with a VUV-IS and a standard $20 \mathrm{mCi}{ }^{210} \mathrm{Po}$ ion source (NRD Static Control, P-2031) on both a commercial high-resolution time-of-flight CIMS (TOF-CIMS) and a Q-CIMS. We also test the potential of measuring PAN using this VUV-IS on a TD (thermal dissociation)-CIMS. The reliability of the VUV-IS is tested by performing field measurements for a 6 -week time period at a remote location. The potential of extending the use of VUV-IS to $\mathrm{SF}_{6}^{-}$and airborne operation is also explored.

\section{Materials and methods}

\subsection{Quadrupole $\mathrm{I}^{-}$-CIMS and experimental configurations}

The Q-CIMS used here is very similar to the system that has measured a variety of species, such as $\mathrm{Cl}_{2}, \mathrm{BrO}$, and PAN, and has been detailed in previous publications (Slusher et al., 2004; Liao et al., 2011, 2014; Lee et al., 2020). Details specific to these experiments are described below. A diagram of the $\mathrm{I}^{-}$-CIMS system and the experimental layout is shown in Fig. 1. Varying levels of calibration standard were added to 4-10 standard liters per minute (sLpm) of $\mathrm{N}_{2}$ and delivered to the sampling inlet of the CIMS through perfluoroalkoxy (PFA) Teflon tubing, with dimensions of $1.27 \mathrm{~cm}$ outer diameter and $0.95 \mathrm{~cm}$ inner diameter. Approximately $1.6 \mathrm{sLpm}$ of this flow was sampled into the CIMS flow tube and the rest was exhausted into the lab. The flow tube was humidified by adding 20 standard cubic centimeters per minute $(\mathrm{sccm})$ of $\mathrm{N}_{2}$ through a water bubbler kept in an ice bath. The flow tube was operated at a pressure of either 27 or $53 \mathrm{hPa}$ by using either a 0.91 or $0.635 \mathrm{~mm}$ orifice between the flow tube and the collisional dissociation chamber (CDC). The scroll pump flow was controlled to maintain the flow tube at 27 or $53 \mathrm{hPa}$.

Mass spectra of ambient Atlanta air were obtained in order to check for potential interferences due to the VUV-IS. For these experiments air was sampled from the roof of the Envi- 


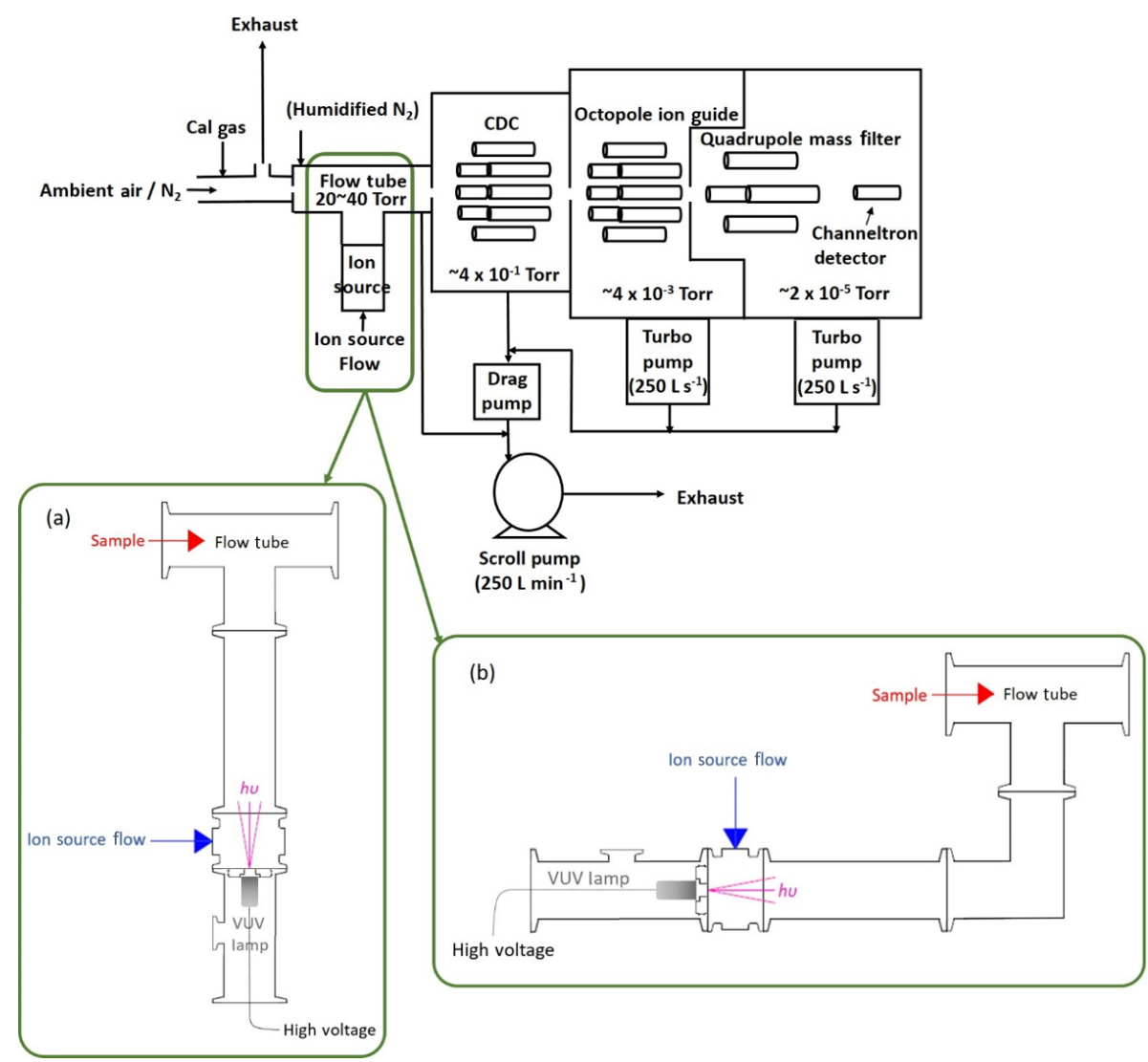

Figure 1. Diagram of the $\mathrm{I}^{-}$-Q-CIMS system with a VUV-IS in two different configurations. Configuration (a) provides the most direct route for the generated ions but also directly illuminates the flow tube. Configuration (b) shields the flow tube from the VUV photons by inserting a QF 40 elbow between the photoionization region and the flow tube.

ronmental Science and Technology building on the Georgia Tech campus. A PFA Teflon tube of $0.95 \mathrm{~cm}$ inner diameter and $8 \mathrm{~m}$ length was used as a sampling inlet. A total flow of $\sim 7 \mathrm{sLpm}$ of ambient air was drawn through the inlet, of which $1.7 \mathrm{sLpm}$ was sampled into the CIMS flow tube and the rest was exhausted through a diaphragm pump. The flow tube was controlled at $27 \mathrm{hPa}$.

\subsection{Calibration sources}

Permeation tubes (KIN-TEK Laboratories, Inc.) were used as the sources of $\mathrm{Cl}_{2}$ and formic acid for tests on the QCIMS. The output of the formic acid tube was measured by ion chromatography (Metrohm Herisau, 761 Compact IC) as detailed by $\mathrm{Nah}$ et al. (2018). The $\mathrm{Cl}_{2}$ permeation tube emission rate was measured by conversion to $\mathrm{I}_{3}^{-}$in aqueous solution, and the resulting $\mathrm{I}_{3}^{-}$was quantified by optical absorption at $352 \mathrm{~nm}$ on a spectrophotometer (Finley and Saltzman, 2008). The permeation rates were measured to be $104.7 \pm 7.8 \mathrm{ng} \mathrm{min}^{-1}$ for formic acid and $14.8 \pm 1.2 \mathrm{ng} \mathrm{min}^{-1}$ for $\mathrm{Cl}_{2}$. A ClNO $\mathrm{Cl}_{2}$ standard was generated by passing a humidified flow of $\mathrm{Cl}_{2}$ from the permeation tube in $\mathrm{N}_{2}$ through a bed of sodium nitrite $\left(\mathrm{NaNO}_{2}\right)$. The yield of $\mathrm{ClNO}_{2}$ from
$\mathrm{Cl}_{2}$ was assumed to be $50 \%$ as we have consistently found in previous studies (Liu et al., 2017).

Sensitivity tests to formic acid and $\mathrm{Cl}_{2}$ on a TOF-CIMS were performed by standard addition in laboratory air. The calibration species were obtained from a calibrated formic acid permeation device $\left(47 \mathrm{ng} \mathrm{min}^{-1}\right)$ and a $4 \mathrm{ppm} \mathrm{Cl}_{2}$ in $\mathrm{N}_{2}$ compressed gas cylinder. The $\mathrm{Cl}_{2}$ cylinder was calibrated by cavity ring-down spectroscopy (CRDS) at $405 \mathrm{~nm}$. The permeation rate of formic acid was measured by catalytic conversion to $\mathrm{CO}_{2}$ followed by $\mathrm{CO}_{2}$ detection as detailed by Veres et al. (2010).

\subsection{VUV ion source (VUV-IS)}

In a typical $\mathrm{I}^{-}$-CIMS system, a flow of $\mathrm{CH}_{3} \mathrm{I}$ in $\mathrm{N}_{2}$ passes through a ${ }^{210} \mathrm{Po}$ radioactive ion source to form the reagent ion $\mathrm{I}^{-}$. In this study, the radioactive source was removed and replaced with a VUV lamp assembly. The $\mathrm{Kr}$ lamp is powered by a $4 \mathrm{~W}$ DC power supply (UltraVolt ${ }^{\circledR}$ AA Series HighVoltage Biasing Supplies). Two configurations (a and b, as shown in Fig. 1) of the VUV lamp assembly were tested. In both configurations a small Kr VUV lamp (Heraeus, Type No. PKS 106) (19.6 mm diameter $\times 53.5 \mathrm{~mm}$ length) was 
used to generate ions. This lamp is commonly used in small commercial volatile organic compound (VOC) detectors that utilize photoionization as a detection method. The lifetime of this lamp is estimated to be $4000 \mathrm{~h}(\sim 5.5$ months of continuous use) by the manufacturer. The VUV lamp was operated at $\sim 280 \mathrm{~V} \mathrm{DC}$ and typically drew $\sim 0.7 \mathrm{~mA}$. In general, the ion current reaching the mass spectrometer increased with increasing lamp voltage (see Fig. S1 in the Supplement). The VUV lamp was attached to a custom QF 40 centering ring with vacuum epoxy. The centering ring has a through hole (11.4 mm diameter) with a counterbore $(41.1 \mathrm{~mm}$ diameter) in the center. The lamp is sealed to the edge of the counterbore with vacuum epoxy. The through hole allows light from the lamp to enter the ion source region of the CIMS. The QF 40 centering ring is mated on the low-pressure side to an inline tee with two QF 40 flanges on the ends and a $0.635 \mathrm{~cm}$ National Pipe Thread (NPT) fitting in the center. In lamp configuration (a), the inline tee is attached to a standard short QF 40 nipple (126 mm length) which serves as a photoionization region and provides a direct path for the VUV photons and generated ions into the flow tube. In configuration (b), a QF $4090^{\circ}$ elbow was attached between the QF 40 nipple and CIMS flow tube to prevent direct exposure of the flow tube to the VUV photons. The ambient pressure side of the QF 40 centering ring, on which the VUV lamp attached, is mated to a QF $40 \times \mathrm{QF} 16 \times \mathrm{QF} 40$, reducing tee housing for protection of the VUV lamp. The QF 16 branch of the tee enables visual inspection of the lamp operation.

The sensitivity of the VUV-IS for measuring formic acid, $\mathrm{Cl}_{2}$, and $\mathrm{ClNO}_{2}$ was measured for varying $\mathrm{CH}_{3} \mathrm{I}$ concentrations and at two flow tube pressures (Tables 1 and 2). The impact of adding $\mathrm{C}_{6} \mathrm{H}_{6}$ was investigated by varying the concentration of $\mathrm{C}_{6} \mathrm{H}_{6}$ at a lower level of $\mathrm{CH}_{3} \mathrm{I}$. Compressed gas cylinders of $\sim 700$ ppmv of $\mathrm{CH}_{3} \mathrm{I}$ and $\sim 0.1 \%$ of $\mathrm{C}_{6} \mathrm{H}_{6}$ in $\mathrm{N}_{2}$ were used as $\mathrm{CH}_{3} \mathrm{I}$ and $\mathrm{C}_{6} \mathrm{H}_{6}$ sources. A variable flow of $\mathrm{N}_{2}$ containing $\mathrm{CH}_{3} \mathrm{I}$ was delivered to the ion source to determine the optimal flow (Fig. 2). The total ion source flow was regulated at $1 \mathrm{sLpm}$ for lamp configuration (a) and $1.2 \mathrm{sLpm}$ for lamp configuration (b) in all sensitivity and interference tests. Mixing ratios of $\mathrm{CH}_{3} \mathrm{I}$ and $\mathrm{C}_{6} \mathrm{H}_{6}$ mentioned in the following sections are the mixing ratios in the total ion source flow (1 or $1.2 \mathrm{sLpm})$.

\subsection{TOF-CIMS}

The VUV-IS was also characterized by operation on a commercial TOF-CIMS (Aerodyne Research Incorporated) (Lee et al., 2014; Veres et al., 2020). The ion molecule reactor (IMR) used here was constructed from a $150 \mathrm{~mm}$ long QF 40 adapter tee with a $9.5 \mathrm{~mm}$ fitting in the center to allow mounting of the VUV-IS. The VUV lamp mounted to the QF 40 inline tee (Sect. 2.1) was attached to a QF $40 \times$ QF 16 conical adapter connected to a flange with a $9.5 \mathrm{~mm}$ stainless steel tube. This allowed the VUV-IS assembly to be mated directly to the IMR using standard vacuum components. The

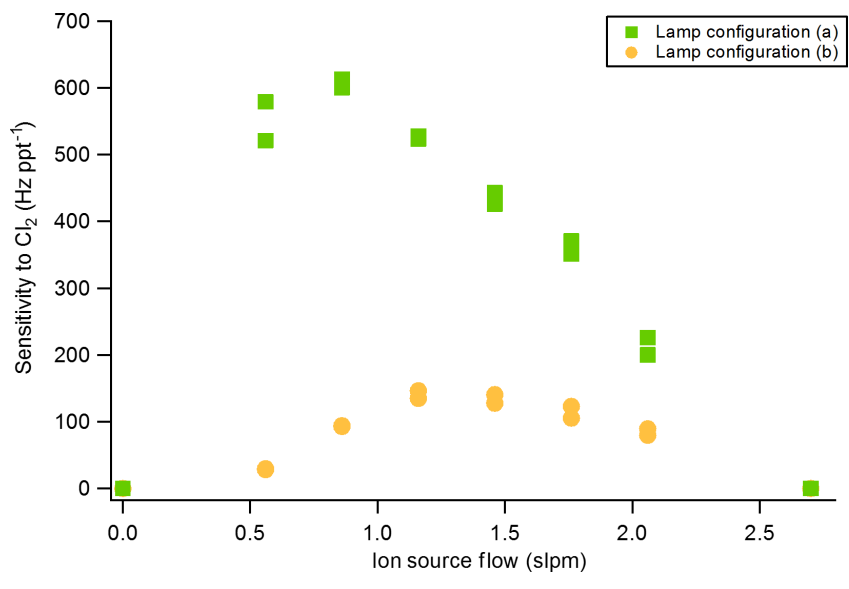

Figure 2. Q-CIMS sensitivity to $\mathrm{Cl}_{2} \cdot \mathrm{I}^{-}(\mathrm{m} / z=197 \mathrm{amu})$ as a function of total ion source flow using the VUV-IS with lamp configuration (a) and (b).

IMR was maintained at a pressure of $40 \mathrm{hPa}$ and operated at a total flow of $2.2 \mathrm{sLpm}$. A $1 \mathrm{sLpm} \mathrm{N} \mathrm{N}_{2}$ flow with 30 400 ppmv $\mathrm{CH}_{3} \mathrm{I}$ passed through the VUV-IS into the IMR and mixed with $1.2 \mathrm{sLpm}$ of ambient air. Water was dynamically added to the IMR to maintain a constant ratio of $\mathrm{I}^{-}$to $\mathrm{I}^{-}\left(\mathrm{H}_{2} \mathrm{O}\right)$. This provided real-time compensation for changes in ambient humidity to minimize fluctuations in sensitivity. Mass spectra were obtained with both a VUV-IS and a standard radioactive ion source, sampling ambient air in Boulder, Colorado.

\subsection{TD-CIMS}

The sensitivity of TD-CIMS with a VUV-IS (Slusher et al., 2004) was also tested for PAN. The configuration of the TDCIMS system used in this work is almost identical to that described in Lee et al. (2020) with the radioactive source replaced with the VUV-IS in configuration (b). A known amount of PAN was generated using a photolytic source similar to that described by Warneck and Zerbach (1992). A calibration standard of 1 ppbv of PAN was produced by adding the output of the photolytic source to PAN-free ambient air. PAN-free air was generated by passing ambient air through a QF 40 nipple filled with stainless steel wool heated to $150^{\circ} \mathrm{C}$ (Flocke et al., 2005).

\section{$2.6 \mathrm{SF}_{6}^{-}$-CIMS}

The instrument used to test the VUV-IS with $\mathrm{SF}_{6}^{-}$as a reagent ion is nearly identical to that used previously to measure $\mathrm{BrO}$ on the National Center for Atmospheric Research (NCAR) Gulfstream-V (GV) research aircraft (Chen et al., 2016). The operating parameters of the instrument are very similar to those used previously to simultaneously detect sulfur dioxide, formic acid, and acetic acid (Nah et al., 2018). However, in this application the radioactive ion source 
Table 1. Experiment conditions, sensitivities, and limits of detection (LODs) for VUV-IS configuration (b).

\begin{tabular}{|c|c|c|c|c|c|}
\hline Exp. & & $\mathrm{CH}_{3} \mathrm{I}$ only & $\mathrm{CH}_{3} \mathrm{I}$ and $\mathrm{C}_{6} \mathrm{H}_{6}$ & $\mathrm{CH}_{3} \mathrm{I}$ only & $\mathrm{CH}_{3} \mathrm{I}$ and $\mathrm{C}_{6} \mathrm{H}_{6}$ \\
\hline Flow tube pressure $(\mathrm{hPa})$ & & 27 & 27 & 53 & 53 \\
\hline $\mathrm{CH}_{3} \mathrm{I}$ mixing ratio (ppmv) & & $8.8-86.5$ & 8.8 & $1.8-19.0$ & 1.8 \\
\hline $\mathrm{C}_{6} \mathrm{H}_{6}$ mixing ratio (ppmv) & & 0 & $0-229.2$ & 0 & $0-58.9$ \\
\hline Formic acid & $\begin{array}{l}\text { sensitivity }\left(\mathrm{Hzpptv}^{-1}\right)^{\mathrm{a}} \\
1 \text { min LOD }(\mathrm{pptv})^{\mathrm{a}, \mathrm{b}}\end{array}$ & $\begin{array}{r}79-147 \\
0.78-0.74\end{array}$ & $\begin{array}{r}79-158 \\
0.78-0.67\end{array}$ & $\begin{array}{r}77-128 \\
0.88-0.62\end{array}$ & $\begin{array}{r}77-157 \\
0.88-0.67\end{array}$ \\
\hline $\mathrm{Cl}_{2}$ & $\begin{array}{l}\text { sensitivity }\left(\mathrm{Hzpptv}^{-1}\right)^{\mathrm{a}} \\
1 \text { min LOD }(\mathrm{pptv})^{\mathrm{a}, \mathrm{b}}\end{array}$ & $\begin{array}{r}83-161 \\
0.82-0.72\end{array}$ & $\begin{array}{r}83-157 \\
0.82-0.68\end{array}$ & $\begin{array}{r}79-149 \\
0.92-0.64\end{array}$ & $\begin{array}{r}79-166 \\
0.92-0.52\end{array}$ \\
\hline $\mathrm{ClNO}_{2}$ & $\begin{array}{l}\text { sensitivity }\left(\mathrm{Hzpptv}^{-1}\right)^{\mathrm{a}} \\
1 \text { min LOD (pptv) }\end{array}$ & $\begin{array}{r}77-154 \\
0.45-0.24\end{array}$ & $\begin{array}{r}77-152 \\
0.45-0.31\end{array}$ & $\begin{array}{r}85-148 \\
0.43-0.17\end{array}$ & $\begin{array}{r}85-138 \\
0.43-0.19\end{array}$ \\
\hline
\end{tabular}

${ }^{a}$ Sensitivities and detection limits are for $\mathrm{HCOOH} \cdot \mathrm{I}^{-}(\mathrm{m} / \mathrm{z}=173 \mathrm{amu}), \mathrm{Cl}_{2} \cdot \mathrm{I}^{-}(\mathrm{m} / z=197 \mathrm{amu})$, and $\mathrm{ClNO}_{2} \cdot \mathrm{I}^{-}(\mathrm{m} / \mathrm{z}=208 \mathrm{amu})$.

${ }^{\mathrm{b}}$ Signal to noise ratio $=3: 1$.

Table 2. Experiment conditions, sensitivities and limits of detection (LODs) for VUV-IS configuration (a).

\begin{tabular}{|c|c|c|c|c|c|}
\hline Exp. & & $\mathrm{CH}_{3} \mathrm{I}$ only & $\mathrm{CH}_{3} \mathrm{I}$ and $\mathrm{C}_{6} \mathrm{H}_{6}$ & $\mathrm{CH}_{3} \mathrm{I}$ only & $\mathrm{CH}_{3} \mathrm{I}$ and $\mathrm{C}_{6} \mathrm{H}_{6}$ \\
\hline Flow tube pressure $(\mathrm{hPa})$ & & 27 & 27 & 53 & 53 \\
\hline $\mathrm{CH}_{3} \mathrm{I}$ mixing ratio (ppmv) & & $9.6-83$ & 9.6 & $1.6-19$ & 1.6 \\
\hline $\mathrm{C}_{6} \mathrm{H}_{6}$ mixing ratio (ppmv) & & 0 & $0-175$ & 0 & $0-54$ \\
\hline \multirow[t]{2}{*}{ Formic acid } & sensitivity $\left(\mathrm{Hzpptv}^{-1}\right)^{\mathrm{a}}$ & $228-761$ & $225-761$ & $171-591$ & $171-703$ \\
\hline & $1 \min \operatorname{LOD}(p p t v)^{a, b}$ & $0.44-0.36$ & $0.59-0.23$ & $0.52-0.28$ & $0.68-0.21$ \\
\hline \multirow[t]{2}{*}{$\mathrm{Cl}_{2}$} & sensitivity $\left(\mathrm{Hzpptv}^{-1}\right)^{\mathrm{a}}$ & $212-754$ & $210-740$ & $173-605$ & $173-694$ \\
\hline & $1 \min \operatorname{LOD}(p p t v)^{\mathrm{a}, \mathrm{b}}$ & $0.56-0.30$ & $0.49-0.27$ & $0.62-0.24$ & $0.48-0.24$ \\
\hline \multirow[t]{2}{*}{$\mathrm{ClNO}_{2}$} & sensitivity $\left(\mathrm{Hzpptv}^{-1}\right)^{\mathrm{a}}$ & $193-687$ & $204-679$ & $153-570$ & $169-605$ \\
\hline & $1 \min \operatorname{LOD}(p p t v)^{\mathrm{a}, \mathrm{b}}$ & $0.22-0.12$ & $0.20-0.10$ & $0.07-0.05$ & $0.12-0.07$ \\
\hline
\end{tabular}

a Sensitivities and detection limits are for $\mathrm{HCOOH} \cdot \mathrm{I}^{-}(\mathrm{m} / z=173 \mathrm{amu}), \mathrm{Cl}_{2} \cdot \mathrm{I}^{-}(\mathrm{m} / z=197 \mathrm{amu})$, and $\mathrm{ClNO}_{2} \cdot \mathrm{I}^{-}(\mathrm{m} / z=208 \mathrm{amu})$.

${ }^{\mathrm{b}}$ Signal to noise ratio $=3: 1$

was replaced with a VUV-IS in configuration (b). The system was periodically calibrated in-flight by adding a known amount of isotopically labeled ${ }^{34} \mathrm{SO}_{2}$ into the sampled air flow.

\section{Results}

\subsection{Q-CIMS sensitivities using $\mathrm{CH}_{3} \mathrm{I}$}

The sensitivities and LODs for formic acid, $\mathrm{Cl}_{2}$, and $\mathrm{ClNO}_{2}$ under different experimental conditions using lamp configuration (b) are compiled in Table 1 . With the flow tube at $27 \mathrm{hPa}$, sensitivities to formic acid, $\mathrm{Cl}_{2}$, and $\mathrm{ClNO}_{2}$ reached up to 147,161 , and $154 \mathrm{Hzptv}^{-1}$, respectively, using up to $86.5 \mathrm{ppmv}$ of $\mathrm{CH}_{3} \mathrm{I}$ in the ion source flow. At $53 \mathrm{hPa}$, similar sensitivities $\left(128,149\right.$, and $148 \mathrm{~Hz} \mathrm{pptv}^{-1}$ for formic acid, $\mathrm{Cl}_{2}$, and $\mathrm{ClNO}_{2}$, respectively) were achieved with less $\mathrm{CH}_{3} \mathrm{I}$ $(19.0$ ppmv). Figure 3 shows the dependence of the CIMS sensitivities on the $\mathrm{CH}_{3} \mathrm{I}$ level at $27 \mathrm{hPa}$ (i) and $53 \mathrm{hPa}$ (iii) with no other absorber added. In general, CIMS sensitivities increase with the $\mathrm{CH}_{3} \mathrm{I}$ mixing ratio. However, the response is less than linear and appears to saturate at higher levels of absorber. With the maximum concentration of $\mathrm{CH}_{3} \mathrm{I}$ $\left(86.5 \mathrm{ppmv}, 5.70 \times 10^{13}\right.$ molecule $\left.\mathrm{cm}^{-3}\right)$ used in this experiment, $\sim 8 \%$ of photons emitted from the VUV lamp were absorbed (see the Supplement for sample calculation). This indicates that other factors such as ion recombination and wall loss limit the ion abundance. The sensitivities and LODs under similar experimental conditions using lamp configuration (a) are shown in Table 2 and Fig. 4. The sensitivities to formic acid, $\mathrm{Cl}_{2}$, and $\mathrm{ClNO}_{2}$ approached $\sim 700 \mathrm{~Hz} \mathrm{pptv}^{-1}$, with limits of detection of less than $1 \mathrm{pptv}$ for a $1 \mathrm{~min}$ integration period. Limits of detection are defined at a signalto-noise ratio of 3 where the noise is the variance of the background measurements. In general, the sensitivities using lamp configuration (a) were about a factor of 4 larger 
than in configuration (b). Note that all the Q-CIMS sensitivities reported in this work are not normalized to the reagent ion signal, since the reagent ion signal is not known accurately. We estimate the reagent ion signals are $\sim 100 \mathrm{MHz}$ at the highest sensitivities, but the Q-CIMS detector counts ions linearly only up to about $0.5 \mathrm{MHz}$.

\subsection{Q-CIMS sensitivities using $\mathrm{CH}_{3} \mathrm{I}$ and $\mathrm{C}_{6} \mathrm{H}_{6}$}

In order to test the effectiveness of the addition of another absorber to generate photoelectrons, mixtures of $\mathrm{CH}_{3} \mathrm{I}$ and $\mathrm{C}_{6} \mathrm{H}_{6}$ were added to the ion source. Lower mixing ratios (8.8 ppmv at 20 Torr, 1.8 ppmv at 40 Torr) of $\mathrm{CH}_{3}$ I were used in combination with varying amounts of $\mathrm{C}_{6} \mathrm{H}_{6}$ to assess the impact of the addition of $\mathrm{C}_{6} \mathrm{H}_{6}$ to the generated ion current using lamp configuration (b). The sensitivity dependence on $\mathrm{C}_{6} \mathrm{H}_{6}$ mixing ratio is shown in Fig. 3. At $27 \mathrm{hPa}$, up to 229.2 ppmv $\mathrm{C}_{6} \mathrm{H}_{6}$ was added to 8.8 ppmv $\mathrm{CH}_{3} \mathrm{I}$ to achieve the equivalent sensitivity $\left(158,157\right.$, and $152 \mathrm{Hzpptv}^{-1}$ for formic acid, $\mathrm{Cl}_{2}$ and $\mathrm{ClNO}_{2}$, respectively) using $86.5 \mathrm{ppmv}$

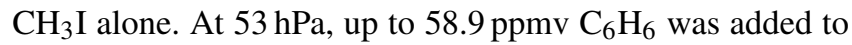
1.8 ppmv of $\mathrm{CH}_{3} \mathrm{I}$ to reach the maximum level of sensitivities $\left(157,166\right.$, and $138 \mathrm{Hzpptv}^{-1}$ for formic acid, $\mathrm{Cl}_{2}$ and $\mathrm{ClNO}_{2}$, respectively) when using 19.0 ppmv of $\mathrm{CH}_{3} \mathrm{I}$. Similar trends for the addition of $\mathrm{C}_{6} \mathrm{H}_{6}$ using lamp configuration (a) was observed and are shown in Table 2 and Fig. 4. At both 27 and $53 \mathrm{hPa}$ sensitivities of more than $600 \mathrm{~Hz} \mathrm{pptv}^{-1}$ were obtained for all species in configuration (a). These results demonstrate that addition of an absorber (e.g., $\mathrm{C}_{6} \mathrm{H}_{6}$ ) enables high sensitivity with the VUV-IS while adding typical levels (a few ppmv) of an electron-attaching compound.

\subsection{Q-CIMS interference tests}

Representative mass spectra $(\mathrm{m} / \mathrm{z}=20-220 \mathrm{amu})$ taken with a $20 \mathrm{mCi}{ }^{210} \mathrm{Po}$ standard radioactive source and the VUVIS with configuration (a) on an $\mathrm{I}^{-}$-CIMS sampling ambient air are shown in Fig. 5. Note that the $\mathrm{I}^{-}$signal is saturated in all mass spectra due to the very high signal levels. Clearly, the VUV-IS in configuration (a) generates many additional ions compared to a radioactive source. Large signals $(>100000 \mathrm{~Hz})$ are observed at $\mathrm{O}_{2}^{-}(m / z=32 \mathrm{amu}), \mathrm{NO}_{3}^{-}$ $(\mathrm{m} / z=62 \mathrm{amu})$, and $\mathrm{CO}_{3}^{-}(\mathrm{m} / z=60 \mathrm{amu})$. This indicates that photoelectrons generated on the illuminated surface of the flow tube in the presence of the sampled air leads to formation of $\mathrm{O}_{2}^{-}$by electron attachment to $\mathrm{O}_{2}$. This also leads to the formation of $\mathrm{CO}_{3}^{-}$and $\mathrm{NO}_{3}^{-}$by subsequent reactions with $\mathrm{CO}_{2}, \mathrm{O}_{3}$, and $\mathrm{NO}_{2}$ (Mohler and Arnold, 1991). Consequently, the generation of $\mathrm{O}_{2}^{-}$initiates significant secondary chemistry that may lead to interfering signals at a large number of masses.

Using the VUV-IS in configuration (b) prevents direct illumination of the flow tube by the VUV lamp and produces similar spectra to those obtained with a radioactive source (Fig. 5). The $\mathrm{O}_{2}^{-}$signal levels are lower by more than 3 or- ders of magnitude compared to configuration (a) where the flow tube is directly illuminated.

Finally, Fig. 5 also has a mass spectrum using the VUV-IS in configuration (b) with the addition of $110 \mathrm{ppmv}$ of $\mathrm{C}_{6} \mathrm{H}_{6}$ and $8.8 \mathrm{ppmv}$ of $\mathrm{CH}_{3} \mathrm{I}$ in the ion source flow. The addition of the $\mathrm{C}_{6} \mathrm{H}_{6}$ does not produce significant amounts of new ions, and the mass spectrum is very similar to that obtained without $\mathrm{C}_{6} \mathrm{H}_{6}$. This indicates that using $\mathrm{C}_{6} \mathrm{H}_{6}$ (or other low IP compounds such as toluene or propene) as a light absorber to generate photoelectrons has the potential to extend the use of the VUV-IS to other electron-attaching compounds (e.g., $\mathrm{SF}_{6}, \mathrm{HNO}_{3}$, etc.) that have small absorption cross sections in the VUV or have ionization potentials higher than $10.6 \mathrm{eV}$.

\subsection{Q-CIMS field tests}

Ground-based measurements of $\mathrm{ClNO}_{2}$, dinitrogen pentoxide $\left(\mathrm{N}_{2} \mathrm{O}_{5}\right)$ and formic acid using the $\mathrm{I}^{-}$-CIMS with the VUV-IS were conducted at a rural site in Dongying, China, during the Ozone Photochemistry and Export from China Experiment (OPECE) from 20 March to 22 April 2018. The I ${ }^{-}$CIMS was deployed in a shelter, with neither heating nor air conditioning, in a remote location in a bird sanctuary in the Yellow River Delta. The site experienced intermittent power interruptions and large ambient temperature variations, from -2.5 to $29.1^{\circ} \mathrm{C}$, with the temperature inside the shelter ranging from $\sim 10$ to $40^{\circ} \mathrm{C}$.

The primary goal for the $\mathrm{I}^{-}$-CIMS during the OPECE campaign was to measure halogen-containing compounds. However, we found the presence of halogens to be intermittent. Figure 6 shows representative observations of $\mathrm{ClNO}_{2}$ and $\mathrm{N}_{2} \mathrm{O}_{5}$ for this site when halogens were observed. This figure is consistent with the expected behavior of $\mathrm{ClNO}_{2}$ and $\mathrm{N}_{2} \mathrm{O}_{5}$, both accumulate during nighttime and both decrease after sunrise due to photolysis of $\mathrm{ClNO}_{2}$ and thermal decomposition of $\mathrm{N}_{2} \mathrm{O}_{5}$, followed by photolysis of $\mathrm{NO}_{3}$. $\mathrm{ClNO}_{2}$ is a product of reaction between $\mathrm{N}_{2} \mathrm{O}_{5}$ and chloridecontaining aerosol (Finlayson-Pitts et al., 1989), and $\mathrm{ClNO}_{2}$ and $\mathrm{N}_{2} \mathrm{O}_{5}$ are well correlated $\left(R^{2}=0.94\right.$, Fig. 6ii) during the night (18:00 LT, 12 April to 06:00 LT, 13 April). These measurements of $\mathrm{ClNO}_{2}$ and $\mathrm{N}_{2} \mathrm{O}_{5}$ indicate the performance of the $\mathrm{I}^{-}$-CIMS with the VUV-IS is sufficient to capture atmospheric levels and variability.

$\mathrm{N}_{2} \mathrm{O}_{5}+\mathrm{Cl}^{-}{ }_{(\text {aq })} \rightarrow \mathrm{ClNO}_{2}+\mathrm{NO}_{3}^{-}($aq)

Formic acid, which is routinely measured by $\mathrm{I}^{-}$-CIMS and ubiquitous in the atmosphere as both an emission and a secondary chemical product, was also monitored during the campaign. These observations demonstrate that $\mathrm{I}^{-}$-CIMS with a VUV-IS could be operated continuously for an extended period (Fig. 7). A clogged mass flow controller on the inlet and a scroll pump failure caused brief measurement interruptions on 27 March and in early April. We could not obtain gas mixtures of $\mathrm{CH}_{3} \mathrm{I}$ at this field location, so we used a liquid reservoir as a $\mathrm{CH}_{3} \mathrm{I}$ source. This 

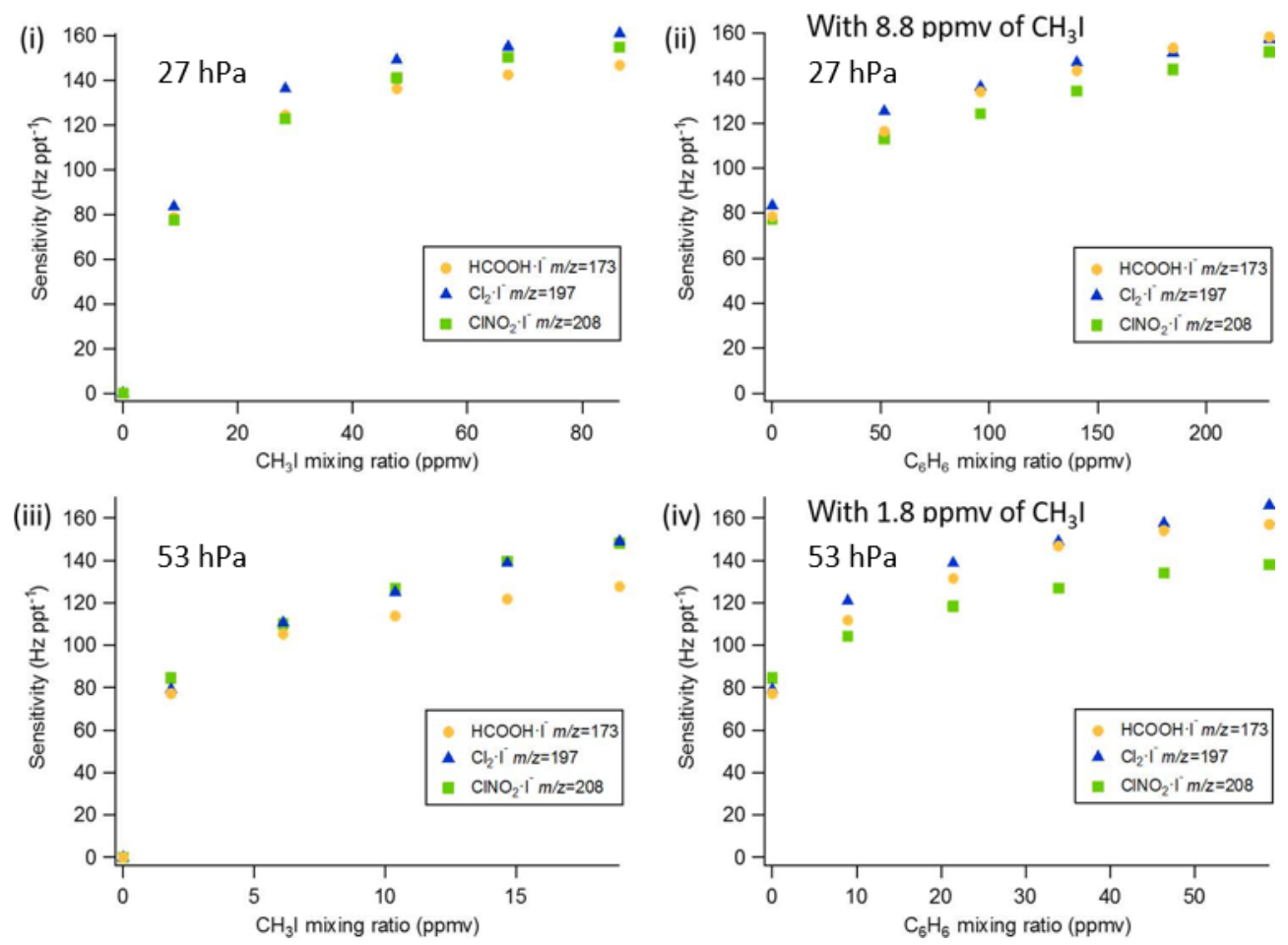

Figure 3. Q-CIMS using VUV-IS configuration (b): (i) sensitivity as a function of $\mathrm{CH}_{3} \mathrm{I}$ at $27 \mathrm{hPa}$, (ii) sensitivity as a function of $\mathrm{C}_{6} \mathrm{H}_{6}$ at $27 \mathrm{hPa}$ with $8.8 \mathrm{ppmv}$ of $\mathrm{CH}_{3} \mathrm{I}$, (iii) sensitivity as a function of $\mathrm{CH}_{3} \mathrm{I}$ at $53 \mathrm{hPa}$, and (iv) sensitivity as a function of $\mathrm{C}_{6} \mathrm{H}_{6}$ at $53 \mathrm{hPa}$ with 1.8 ppmv of $\mathrm{CH}_{3} \mathrm{I}$.
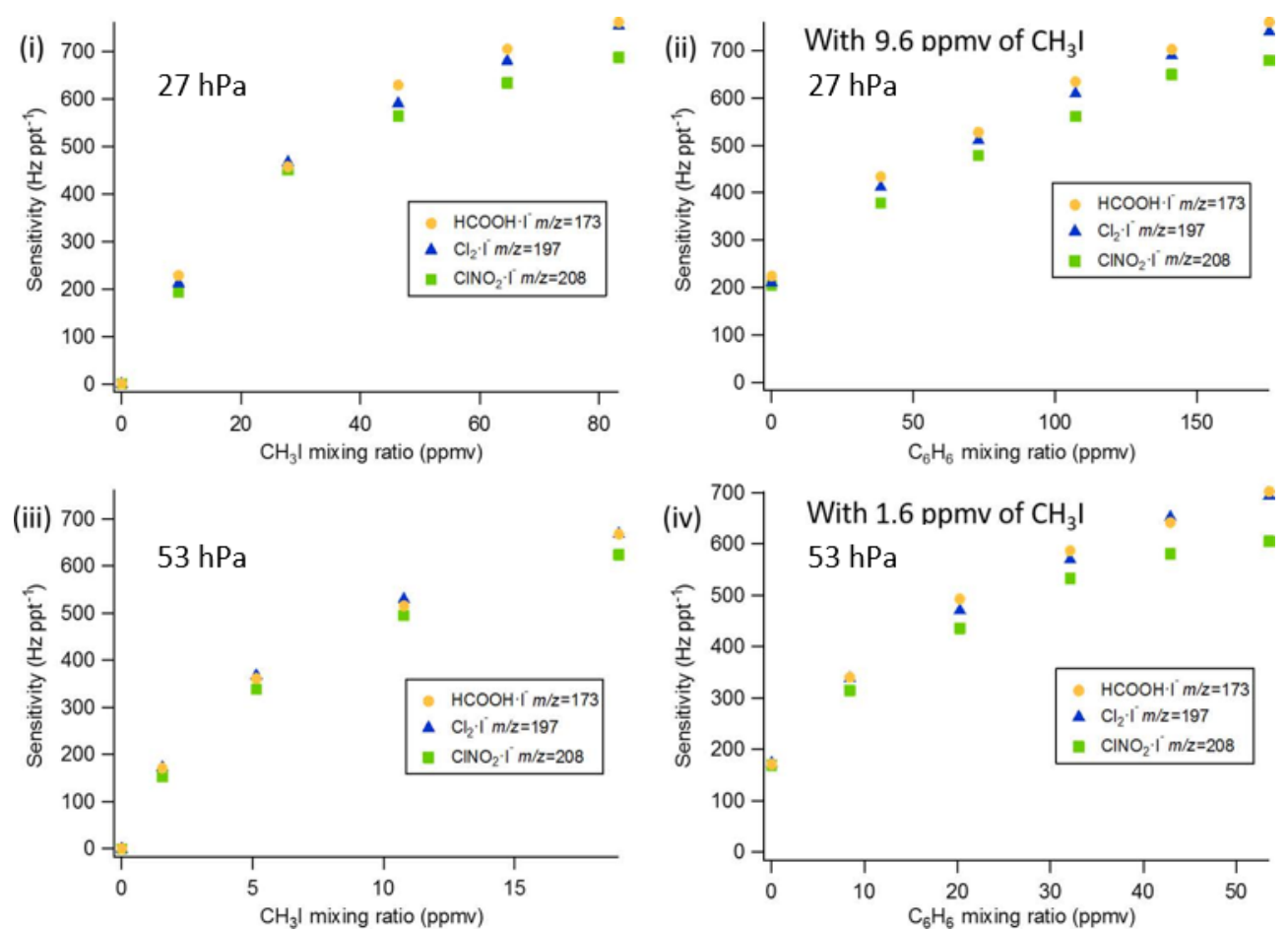

Figure 4. Q-CIMS using VUV-IS configuration (a): (i) sensitivity as a function of $\mathrm{CH}_{3} \mathrm{I}$ at $27 \mathrm{hPa}$, (ii) sensitivity as a function of $\mathrm{C}_{6} \mathrm{H}_{6}$ at $27 \mathrm{hPa}$ with $9.6 \mathrm{ppmv}$ of $\mathrm{CH}_{3} \mathrm{I}$, (iii) sensitivity as a function of $\mathrm{CH}_{3} \mathrm{I}$ at $53 \mathrm{hPa}$, and (iv) sensitivity as a function of $\mathrm{C}_{6} \mathrm{H}_{6}$ at $53 \mathrm{hPa}$ with 1.6 ppmv of $\mathrm{CH}_{3} \mathrm{I}$. 

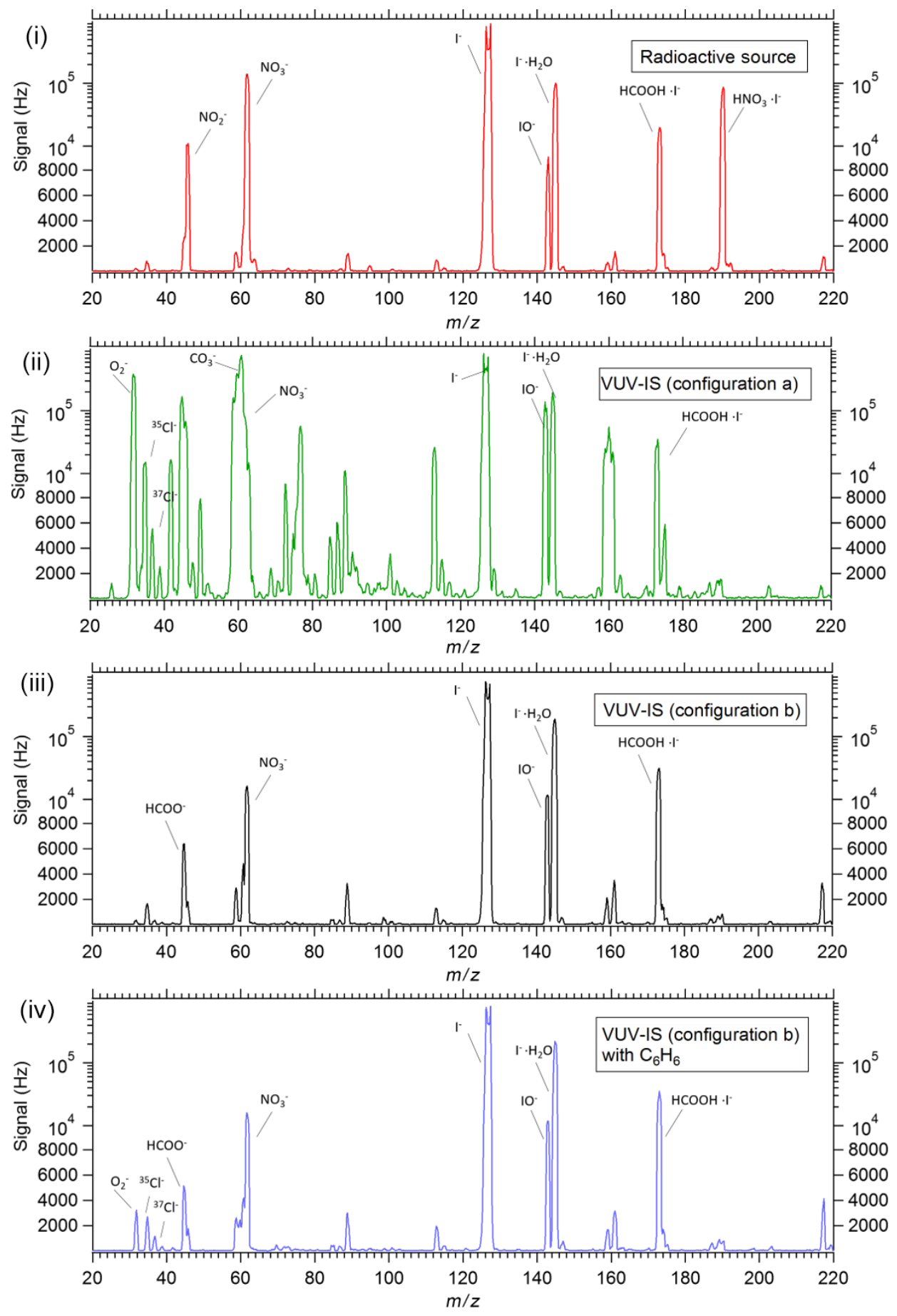

Figure 5. Mass spectra of ambient air from a Q-CIMS with (i) a standard radioactive ion source, (ii) VUV-IS in configuration (a), (iii) VUVIS in configuration (b), and (iv) VUV-IS in configuration (b) with $\sim 100$ ppmv of $\mathrm{C}_{6} \mathrm{H}_{6}$ and $\sim 10$ ppmv of $\mathrm{CH}_{3} \mathrm{I}$. Note that the $\mathrm{I}^{-}$signal is saturated in all mass spectra.

led to using $\mathrm{CH}_{3} \mathrm{I}$ levels of hundreds of ppmv, which may have accelerated degradation of the scroll pump tip seals. We also encountered some temperature control issues and power interruptions during the mission. However, no direct problems were encountered with the VUV-IS. Online cali- bration of formic acid was performed every 30 min during the mission. The CIMS sensitivity to formic acid was measured to be $185.2 \pm 48.3 \mathrm{Hzpptv}^{-1}$ during the first day and $180.5 \pm 24.3 \mathrm{Hzpptv}^{-1}$ a month later, so we did not notice any drop in sensitivity that could be attributed to a decrease 

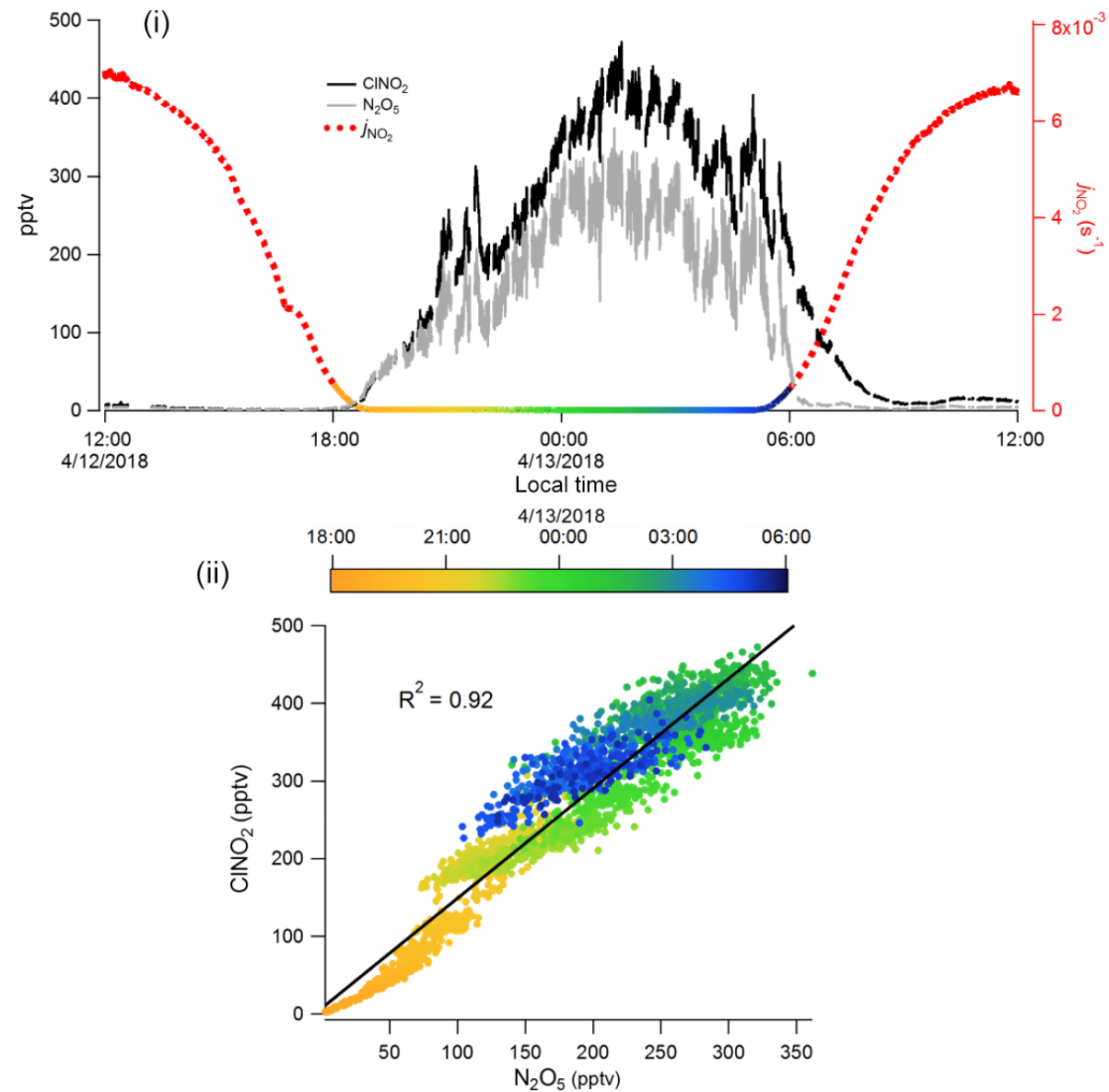

Figure 6. Measurements of $\mathrm{ClNO}_{2}$ and $\mathrm{N}_{2} \mathrm{O}_{5}$ using I- $\mathrm{I}^{-}$CIMS with VUV-IS between 12:00 LT, 12 April and 12:00 LT, 13 April 2018 during the OPECE campaign: (i) time series, along with $j_{\mathrm{NO}_{2}}$ (to delineate night and day), and (ii) a correlation plot of $\mathrm{ClNO}_{2}$ concentration versus $\mathrm{N}_{2} \mathrm{O}_{5}$ concentration during the nighttime (18:00 LT, 12 April, to 06:00 LT, 13 April).

in light intensity from the lamp. In addition, we have used the same VUV-IS since the OPECE field mission (spring 2018) through early 2020 for both lab studies and field measurements and have not found obvious sensitivity degradations.

\subsection{TOF-CIMS tests}

The VUV-IS was found to give very similar signal levels to those obtained with a standard radioactive ion source (with an activity of $\sim 16 \mathrm{mCi}$ of ${ }^{210} \mathrm{Po}$ ) on a TOF-CIMS. Both sources gave total reagent ion signals of $\sim 10 \mathrm{MHz}$ and similar sensitivity to both formic acid and $\mathrm{Cl}_{2}$ of about 20 $25 \mathrm{Hzppt}^{-1}$. The $\mathrm{I}^{-}$signal for both sources was $\sim 6 \mathrm{MHz}$, and the $\mathrm{I}^{-}\left(\mathrm{H}_{2} \mathrm{O}\right)$ signal was $\sim 3 \mathrm{MHz}$. In addition, as illustrated in Fig. 8, both sources gave very similar mass spectra for ambient air. The largest difference between the mass spectra was that the VUV-IS gave higher levels of $\mathrm{I}_{3}^{-}$, while the radioactive source gave higher levels of peaks corresponding to nitric acid (i.e., $\mathrm{I}^{-}\left(\mathrm{HNO}_{3}\right)$ and $\left.\mathrm{NO}_{3}^{-}\right)$. Sensitivities as a function of $\mathrm{CH}_{3} \mathrm{I}$ mixing ratio in the flow tube were also tested (Fig. S2). Sensitivities to formic acid and
$\mathrm{Cl}_{2}$ increase with the $\mathrm{CH}_{3} \mathrm{I}$ mixing ratio up to $\sim 100 \mathrm{ppmv}$. The sensitivities normalized to the reagent ion $\mathrm{I}^{-}\left(\mathrm{H}_{2} \mathrm{O}\right)$ do not change with $\mathrm{CH}_{3} \mathrm{I}$ mixing ratio and are the same as those obtained with the radioactive source. These results demonstrate that a VUV-IS can be used on a TOF-CIMS to obtain the same sensitivity, selectivity, and ion distribution as with a radioactive ion source.

\subsection{PAN measurement tests}

Preliminary tests using the Q-CIMS as a TD-CIMS demonstrated the potential of the VUV-IS for use in the measurement of PAN. Mass spectra of ambient air with and without PAN are shown in Fig. S3. The sensitivity towards PAN was observed to be $49.4 \mathrm{Hzpptv}^{-1}$ with an LOD (signal-to-noise ratio $=3: 1$ ) of $0.64 \mathrm{pptv}$ for a $1 \mathrm{~min}$ integration. No significant interferences were observed during the ambient air tests. 


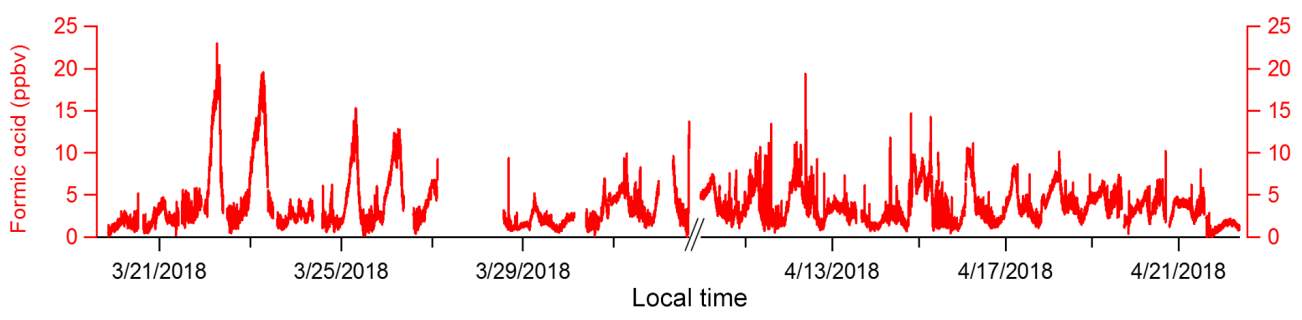

Figure 7. Time series of ambient formic acid concentrations measured by $\mathrm{I}^{-}$-CIMS with VUV-IS from 20 March to 22 April 2018 during the OPECE campaign.
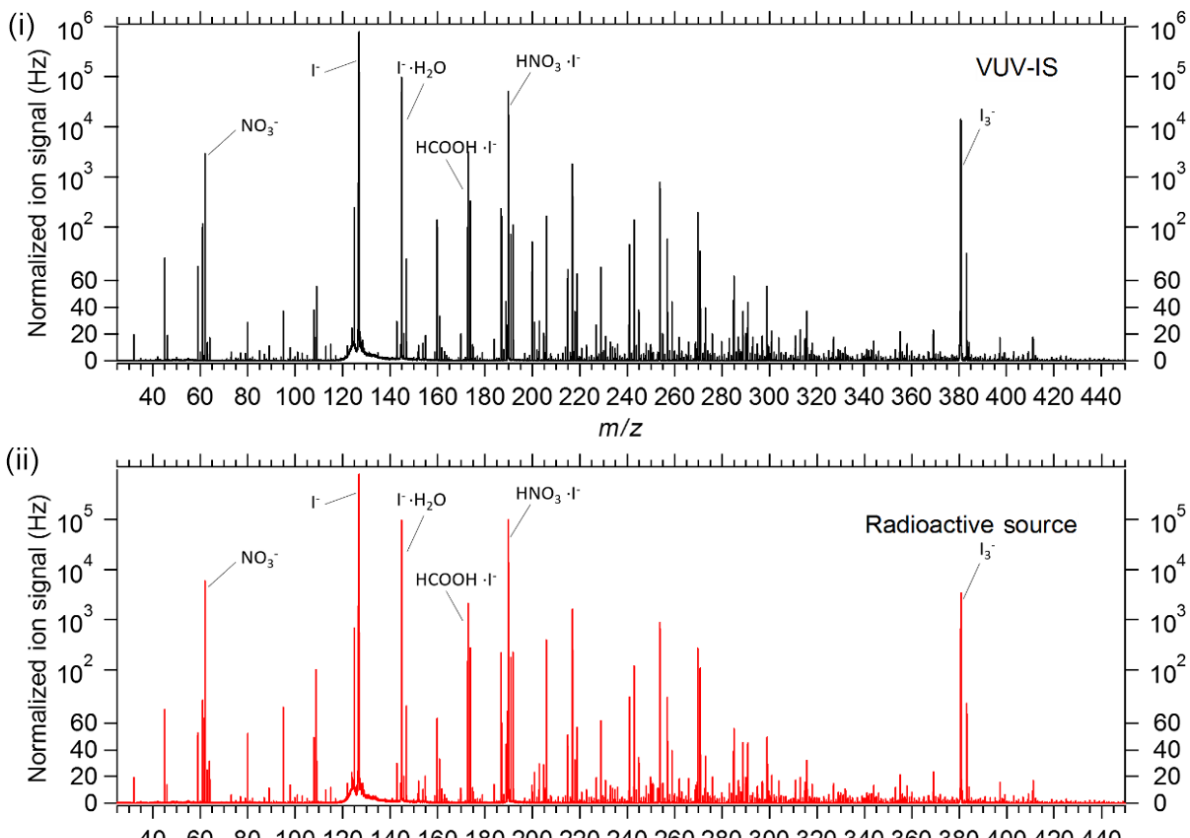

406080100120140160180200220240260280300320340360380400420440

$\mathrm{m} / \mathrm{z}$

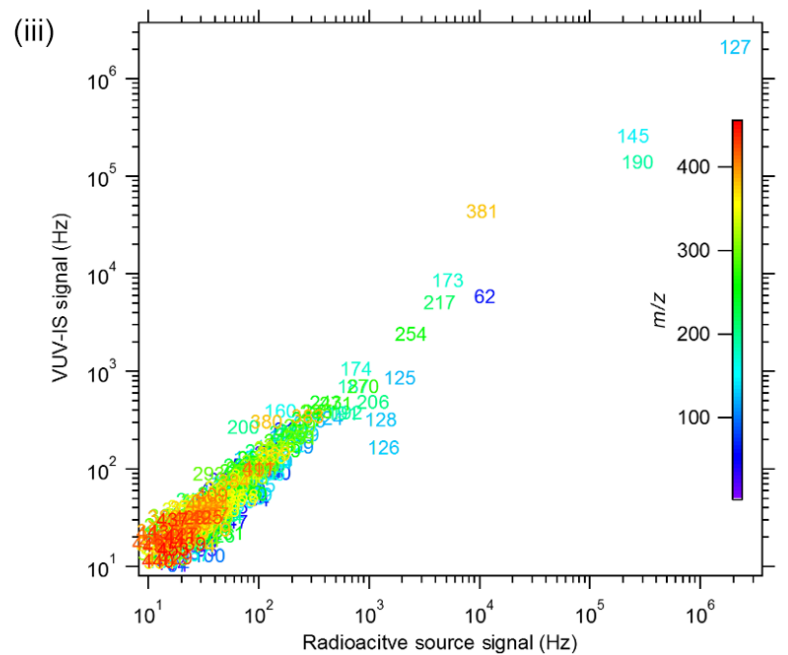

Figure 8. Mass spectra of ambient air in Boulder, Colorado, from a TOF-CIMS with (i) a VUV-IS and (ii) a radioactive source. The bottom panel (iii) is a correlation plot of the individual mass signals with the VUV-IS versus those obtained with a radioactive source, with each ion labeled by its nominal mass. 


\section{7 $\mathrm{SF}_{6}^{-}-\mathrm{Q}$-CIMS tests}

Preliminary aircraft-based measurements of sulfur dioxide and formic and acetic acid using the $\mathrm{SF}_{6}^{-}$-CIMS with the VUV-IS were conducted during an Asian Summer Monsoon Chemical and Climate Impact Project (ACCLIP) test flight based out of Broomfield, Colorado, on 30 January 2020. Time series of formic and acetic acid signals are shown in Fig. S4(1). The signals of formic and acetic acid are correlated $\left(R^{2}=0.63\right.$, Fig. S4(2)) as observed in previous studies (Souza and Carvalho, 2001; Paulot et al., 2011; Nah et al., 2018). We did not perform online calibrations for formic or acetic acid. Sensitivities to formic and acetic acids during this test flight are estimated to be $5-20 \mathrm{~Hz} \mathrm{pptv}^{-1}$ based on online calibrations of ${ }^{34} \mathrm{SO}_{2}$ and measurements of the ratio of their sensitivities (Nah et al., 2018).

\section{Discussion}

The VUV-IS can generate $\mathrm{I}^{-}$ions and mass spectra that are very similar to a radioactive ion source on both a TOF-CIMS and a Q-CIMS. For this reason, we think that the VUV-IS can replace radioactive ion sources in most $\mathrm{I}^{-}$-CIMS applications without any loss of measurement performance. Perhaps the largest benefit of the VUV-IS is that it will expand the use of $\mathrm{I}^{-}$-CIMS to locations or situations where radioactivity is not allowed. The VUV-IS is also likely to be useful for laboratory flow tube or chamber studies that use CIMS as a detector (D'Ambro et al., 2017; Huang et al., 2017; Faxon et al., 2018). We have not found any interferences or issues that would limit application of a VUV-IS, though its application to the measurement of individual species must be confirmed by further testing.

Using the VUV-IS requires attention to the possibility of interferences caused by the generation of photoelectrons from surfaces that can be attached by oxygen or other compounds in the sampled gas matrix. We were able to minimize this effect by using a flow geometry that shielded the flow tube from the VUV photons, albeit at the expense of more than a factor of 4 in signal on the Q-CIMS. Similarly, the implementation of the VUV-IS on the TOF-CIMS successfully limited $\mathrm{O}_{2}^{-}$production by passing the ion source flow through a small diameter tube that discriminated against light reaching the IMR. This issue might also be addressed by further improvements in geometry, the use of optical focusing elements, or higher levels of an absorber molecule.

The VUV-IS source requires an absorbing species to serve as a source of photoelectrons. Extending the use of the VUVIS to other reagent ions such as $\mathrm{SF}_{6}^{-}$(Nah et al., 2018), $\mathrm{Br}^{-}$(Sanchez et al., 2016), $\mathrm{NO}_{3}^{-}$(Eisele and Tanner, 1993), $\mathrm{CF}_{3} \mathrm{O}^{-}$(Crounse et al., 2006), and $\mathrm{CH}_{3} \mathrm{CO}_{2}^{-}$(Veres et al., 2008) requires the addition of an absorber such as $\mathrm{C}_{6} \mathrm{H}_{6}$ or $\mathrm{C}_{7} \mathrm{H}_{8}$. Although the use of $\mathrm{CH}_{3} \mathrm{I}$ to produce $\mathrm{I}^{-}$with the VUV-IS does not require an additional absorber, this appli- cation requires relatively high levels of $\mathrm{CH}_{3} \mathrm{I}$ to obtain maximum sensitivities. Since $\mathrm{CH}_{3} \mathrm{I}$ is a hazardous gas, higher levels of $\mathrm{CH}_{3} \mathrm{I}$ could be problematic for some situations such as deployment in a highly regulated environment such as an aircraft. Higher levels of $\mathrm{CH}_{3} \mathrm{I}$ may also necessitate protection of scroll pumps with scrubbers and traps. For these reasons, it may be preferable to use a low activity (Lee et al., 2020) or standard radioactive ion source for some applications.

One potential advantage of the VUV-IS is demonstrated by the lower background signals at masses corresponding to nitric acid $\left(\mathrm{HNO}_{3}\right)$. This is probably due to lower rates of nitrogen radical generation in the VUV-IS as the generated photons are much lower in energy $(\sim 10 \mathrm{eV})$ relative to the $\alpha$ particles $(\sim 5.4 \mathrm{MeV})$ from a ${ }^{210}$ Po radioactive source. Additionally, the VUV-IS does not produce ions when power is removed but radioactive decay is continuous. Consequently, interfering species can be continuously generated in a radioactive source, leading to a build up of condensable species such as nitric acid. For these reasons, the VUV-IS may generate significantly lower levels of interferences than a radioactive source.

\section{Summary and conclusions}

The sensitivity of the VUV-IS on the Q-CIMS can reach $100 \mathrm{~s}$ of $\mathrm{Hzpptv}^{-1}$ (Tables 1 and 2) similar to the best sensitivity obtained with radioactive sources (e.g., Lee et al., 2020). Care must be taken to avoid illuminating surfaces in the CIMS exposed to air. The VUV-IS requires significantly higher levels of $\mathrm{CH}_{3} \mathrm{I}$ than used in radioactive sources (typically $\sim 1$ ppmv, Slusher et al., 2004) (Figs. 3 and 4) because the $\mathrm{CH}_{3} \mathrm{I}$ must also serve as a source of photoelectrons. $\mathrm{C}_{6} \mathrm{H}_{6}$ and other species can be used as a VUV absorber to generate photoelectrons (Figs. 3 and 4) without generating excessive interferences (Fig. 5). Tests on a TOF-CIMS demonstrated that the VUV-IS and a standard radioactive ion source produced the same reagent ion $\left(\mathrm{I}^{-}\right)$abundance. In addition, both sources generated similar mass spectra of ambient air, demonstrating that the VUV-IS source did not produce significant interferences to the detection of most trace gases (Fig. 8). Preliminary tests also indicate the VUV-IS is compatible with TD-CIMS and $\mathrm{SF}_{6}^{-}$-CIMS methods, as well as airborne operation.

The VUV-IS described in this work provides sensitivities and limits of detections that are at least comparable to those obtained with a radioactive ion source for both Q-CIMS and TOF-CIMS using $\mathrm{I}^{-}$as a reagent ion. The VUV-IS is reliable and can be safely deployed in remote field missions. These results demonstrate that the VUV-IS can eliminate the need for radioactivity with an $\mathrm{I}^{-}$-CIMS for most applications. The use of low IP absorbers, such as $\mathrm{C}_{6} \mathrm{H}_{6}$, to generate photoelectrons in conjunction with high IP electron-attaching compounds allows the generation of other reagent ions such as $\mathrm{SF}_{6}^{-}, \mathrm{CF}_{3} \mathrm{O}^{-}$, and $\mathrm{NO}_{3}^{-}$. In summary, the VUV-IS has the 
potential to eliminate most of the use of radioactivity with CIMS instruments.

Data availability. All of the data used in this work are available upon request of the corresponding author.

Supplement. The supplement related to this article is available online at: https://doi.org/10.5194/amt-13-3683-2020-supplement.

Author contributions. YJ performed all of the Q-CIMS experiments and wrote the manuscript with assistance from LGH. DJT assisted with all of the experiments. XW organized the OPECE campaign and provided the $j_{\mathrm{NO}_{2}}$ data. All of the authors were involved in data interpretation and commented on the manuscript. The TOFCIMS experiments were performed by PRV, JAN, and LGH.

Competing interests. The authors declare that they have no conflict of interest.

Acknowledgements. This work was supported by the NSF and NASA. The OPECE field mission was supported by the NSF. This work was also supported in part by an EPA STAR grant awarded to the Georgia Institute of Technology. It has not been formally reviewed by the EPA. The views expressed in this document are solely those of the authors and do not necessarily reflect those of the EPA. The EPA does not endorse any products or commercial services mentioned in this publication and EPA grant. We thank Jianhui Tang for providing the RH data on the field. We also thank the Yellow River Delta Ecological Research Station of Coastal Wetland, which belongs to the Yantai Institute of Coastal Zone Research, Chinese Academy of Sciences, for logistical support for the OPECE campaign.

Financial support. This research has been supported by the National Science Foundation (grant nos. 1853930 and 1743401), the U.S. Environmental Protection Agency (STAR (grant no. R835882)), and the National Aeronautics and Space Administration (grant no. NNX15AT90G).

Review statement. This paper was edited by Fred Stroh and reviewed by Joachim Franzke and one anonymous referee.

\section{References}

Bertram, T. H., Kimmel, J. R., Crisp, T. A., Ryder, O. S., Yatavelli, R. L. N., Thornton, J. A., Cubison, M. J., Gonin, M., and Worsnop, D. R.: A field-deployable, chemical ionization timeof-flight mass spectrometer, Atmos. Meas. Tech., 4, 1471-1479, https://doi.org/10.5194/amt-4-1471-2011, 2011.
Capalbo, F. J., Benilan, Y., Fray, N., Schwell, M., Champion, N., Es-Sebbar, E. T., Koskinen, T. T., Lehocki, I., and Yelle, R. V.: New benzene absorption cross sections in the VUV, relevance for Titan's upper atmosphere, Icarus, 265, 95-109, https://doi.org/10.1016/j.icarus.2015.10.006, 2016.

Chen, D. X., Huey, L. G., Tanner, D. J., Salawitch, R. J., Anderson, D. C., Wales, P. A., Pan, L. L., Atlas, E. L., Hornbrook, R. S., Apel, E. C., Blake, N. J., Campos, T. L., Donets, V., Flocke, F. M., Hall, S. R., Hanisco, T. F., Hills, A. J., Honomichl, S. B., Jensen, J. B., Kaser, L., Montzka, D. D., Nicely, J. M., Reeves, J. M., Riemer, D. D., Schauffler, S. M., Ullmann, K., Weinheimer, A. J., and Wolfe, G. M.: Airborne measurements of BrO and the sum of $\mathrm{HOBr}$ and $\mathrm{Br}_{2}$ over the Tropical West Pacific from 1 to $15 \mathrm{~km}$ during the CONvective TRansport of Active Species in the Tropics (CONTRAST) experiment, J. Geophys. Res.-Atmos., 121, 12560-12578, 2016.

Crounse, J. D., McKinney, K. A., Kwan, A. J., and Wennberg, P. O.: Measurement of gas-phase hydroperoxides by chemical ionization mass spectrometry, Anal. Chem., 78, 6726-6732, https://doi.org/10.1021/ac0604235, 2006.

D’Ambro, E. L., Lee, B. H., Liu, J., Shilling, J. E., Gaston, C. J., Lopez-Hilfiker, F. D., Schobesberger, S., Zaveri, R. A., Mohr, C., Lutz, A., Zhang, Z., Gold, A., Surratt, J. D., Rivera-Rios, J. C., Keutsch, F. N., and Thornton, J. A.: Molecular composition and volatility of isoprene photochemical oxidation secondary organic aerosol under low- and high- $\mathrm{NO}_{x}$ conditions, Atmos. Chem. Phys., 17, 159-174, https://doi.org/10.5194/acp-17159-2017, 2017.

Eger, P. G., Helleis, F., Schuster, G., Phillips, G. J., Lelieveld, J., and Crowley, J. N.: Chemical ionization quadrupole mass spectrometer with an electrical discharge ion source for atmospheric trace gas measurement, Atmos. Meas. Tech., 12, 1935-1954, https://doi.org/10.5194/amt-12-1935-2019, 2019.

Eisele, F. L. and Tanner, D. J.: Measurement of the GasPhase Concentration of $\mathrm{H}_{2} \mathrm{SO}_{4}$ and Methane SulfonicAcid and Estimates of $\mathrm{H}_{2} \mathrm{SO}_{4}$ Production and Loss in the Atmosphere, J. Geophys. Res.-Atmos., 98, 9001-9010, https://doi.org/10.1029/93jd00031, 1993.

Faxon, C., Hammes, J., Le Breton, M., Pathak, R. K., and Hallquist, M.: Characterization of organic nitrate constituents of secondary organic aerosol (SOA) from nitrate-radical-initiated oxidation of limonene using high-resolution chemical ionization mass spectrometry, Atmos. Chem. Phys., 18, 5467-5481, https://doi.org/10.5194/acp-18-5467-2018, 2018.

Finlayson-Pitts, B. J., Ezell, M. J. and Pitts, J. N.: Formation of chemically active chlorine compounds by reactions of atmospheric $\mathrm{NaCl}$ particles with gaseous $\mathrm{N}_{2} \mathrm{O}_{5}$ and $\mathrm{ClONO}_{2}$, Nature, 337, 241-244, 1989.

Finley, B. D. and Saltzman, E. S.: Observations of $\mathrm{Cl}_{2}, \mathrm{Br}_{2}$, and $\mathrm{I}_{2}$ in coastal marine air, J. Geophys. Res.-Atmos., 113, D21301, https://doi.org/10.1029/2008JD010269, 2008.

Flocke, F. M., Weinheimer, A. J., Swanson, A. L., Roberts, J. M., Schmitt, R., and Shertz, S.: On the measurement of PANs by gas chromatography and electron capture detection, J. Atmos. Chem., 52, 19-43, https://doi.org/10.1007/s10874-005-6772-0, 2005.

Holmes, J. L. and Lossing, F. P.: Ionization Energies of Homologous Organic-Compounds and Correlation with 
Molecular-Size, Org. Mass Spectrom., 26, 537-541, DOI https://doi.org/10.1002/oms.1210260603, 1991.

Huang, Y., Coggon, M. M., Zhao, R., Lignell, H., Bauer, M. U., Flagan, R. C., and Seinfeld, J. H.: The Caltech Photooxidation Flow Tube reactor: design, fluid dynamics and characterization, Atmos. Meas. Tech., 10, 839-867, https://doi.org/10.5194/amt10-839-2017, 2017.

Huey, L. G.: Measurement of trace atmospheric species by chemical ionization mass spectrometry: Speciation of reactive nitrogen and future directions, Mass Spectrometry Reviews, 26, 166-184, https://doi.org/10.1002/mas.20118, 2007.

Jost, C., Sprung, D., Kenntner, T., and Reiner, T.: Atmospheric pressure chemical ionization mass spectrometry for the detection of tropospheric trace gases: the influence of clustering on sensitivity and precision, International Journal of Mass Spectrometry, 223, 771-782, Pii S1387-3806(02)00963-6, Doi https://doi.org/10.1016/S1387-3806(02)00963-6, 2003.

Kauppila, T. J., Syage, J. A., and Benter, T.: Recent Developments in Atmospheric Pressure Photoionization-Mass Spectrometry, Mass Spectrom. Rev., 36, 423-449, 2017.

Kürten, A., Rondo, L., Ehrhart, S., and Curtius, J.: Performance of a corona ion source for measurement of sulfuric acid by chemical ionization mass spectrometry, Atmos. Meas. Tech., 4, 437-443, https://doi.org/10.5194/amt-4-437-2011, 2011

Lee, B. H., Lopez-Hilfiker, F. D., Mohr, C., Kurten, T., Worsnop, D. R., and Thornton, J. A.: An Iodide-Adduct HighResolution Time-of-Flight Chemical-Ionization Mass Spectrometer: Application to Atmospheric Inorganic and Organic Compounds, Environ. Sci. Technol., 48, 6309-6317, https://doi.org/10.1021/es500362a, 2014.

Lee, Y. R., Ji, Y., Tanner, D. J., and Huey, L. G.: A low-activity ion source for measurement of atmospheric gases by chemical ionization mass spectrometry, Atmos. Meas. Tech., 13, 2473-2480, https://doi.org/10.5194/amt-13-2473-2020, 2020.

Liao, J., Sihler, H., Huey, L. G., Neuman, J. A., Tanner, D. J., Friess, U., Platt, U., Flocke, F. M., Orlando, J. J., Shepson, P. B., Beine, H. J., Weinheimer, A. J., Sjostedt, S. J., Nowak, J. B., Knapp, D. J., Staebler, R. M., Zheng, W., Sander, R., Hall, S. R., and Ullmann, K.: A comparison of Arctic BrO measurements by chemical ionization mass spectrometry and long path-differential optical absorption spectroscopy, J. Geophys. Res.-Atmos., 116, D00R02, https://doi.org/10.1029/2010jd014788, 2011.

Liao, J., Huey, L. G., Liu, Z., Tanner, D. J., Cantrell, C. A., Orlando, J. J., Flocke, F. M., Shepson, P. B., Weinheimer, A. J., Hall, S. R., Ullmann, K., Beine, H. J., Wang, Y. H., Ingall, E. D., Stephens, C. R., Hornbrook, R. S., Apel, E. C., Riemer, D., Fried, A., Mauldin, R. L., Smith, J. N., Staebler, R. M., Neuman, J. A., and Nowak, J. B.: High levels of molecular chlorine in the Arctic atmosphere, Nat. Geosci., 7, 91-94, https://doi.org/10.1038/Ngeo2046, 2014.

Liu, X., Qu, H., Huey, L. G., Wang, Y., Sjostedt, S., Zeng, L., Lu, K., Wu, Y., Hu, M., Shao, M., Zhu, T., and Zhang, Y.: High Levels of Daytime Molecular Chlorine and Nitryl Chloride at a Rural Site on the North China Plain, Environ. Sci. Technol., 51, 9588-9595, https://doi.org/10.1021/acs.est.7b03039, 2017.

Mohler, O. and Arnold, F.: Flow Reactor and Triple Quadrupole Mass-Spectrometer Investigations of Negative-Ion Reactions Involving Nitric-Acid - Implications for Atmospheric Hno3 Detection by Chemical Ionization Mass-Spectrometry, J. Atmos. Chem., 13, 33-61, https://doi.org/10.1007/Bf00048099, 1991.
Nah, T., Ji, Y., Tanner, D. J., Guo, H., Sullivan, A. P., Ng, N. L., Weber, R. J., and Huey, L. G.: Real-time measurements of gas-phase organic acids using $\mathrm{SF}_{6}^{-}$chemical ionization mass spectrometry, Atmos. Meas. Tech., 11, 5087-5104, https://doi.org/10.5194/amt-11-5087-2018, 2018.

Nemeth, G. I., Selzle, H. L., and Schlag, E. W.: Magnetic Zeke Experiments with Mass Analysis, Chem. Phys. Lett., 215, 151-155, https://doi.org/10.1016/0009-2614(93)89279-Q, 1993.

Neuman, J. A., Trainer, M., Brown, S. S., Min, K. E., Nowak, J. B., Parrish, D. D., Peischl, J., Pollack, I. B., Roberts, J. M., Ryerson, T. B., and Veres, P. R.: HONO emission and production determined from airborne measurements over the Southeast US, J. Geophys. Res.-Atmos., 121, 9237-9250, https://doi.org/10.1002/2016jd025197, 2016.

Olney, T. N., Cooper, G., and Brion, C. E.: Quantitative studies of the photoabsorption $(4.5-488 \mathrm{eV})$ and photoionization $(9-59.5 \mathrm{eV})$ of methyl iodide using dipole electron impact techniques, Chem. Phys., 232, 211-237, https://doi.org/10.1016/S0301-0104(97)00368-6, 1998.

Osthoff, H. D., Roberts, J. M., Ravishankara, A. R., Williams, E. J., Lerner, B. M., Sommariva, R., Bates, T. S., Coffman, D., Quinn, P. K., Dibb, J. E., Stark, H., Burkholder, J. B., Talukdar, R. K., Meagher, J., Fehsenfeld, F. C., and Brown, S. S.: High levels of nitryl chloride in the polluted subtropical marine boundary layer, Nat. Geosci., 1, 324-328, https://doi.org/10.1038/ngeo177, 2008.

Phillips, G. J., Pouvesle, N., Thieser, J., Schuster, G., Axinte, R., Fischer, H., Williams, J., Lelieveld, J., and Crowley, J. N.: Peroxyacetyl nitrate (PAN) and peroxyacetic acid (PAA) measurements by iodide chemical ionisation mass spectrometry: first analysis of results in the boreal forest and implications for the measurement of PAN fluxes, Atmos. Chem. Phys., 13, 11291139, https://doi.org/10.5194/acp-13-1129-2013, 2013.

Paulot, F., Wunch, D., Crounse, J. D., Toon, G. C., Millet, D. B., DeCarlo, P. F., Vigouroux, C., Deutscher, N. M., González Abad, G., Notholt, J., Warneke, T., Hannigan, J. W., Warneke, C., de Gouw, J. A., Dunlea, E. J., De Mazière, M., Griffith, D. W. T., Bernath, P., Jimenez, J. L., and Wennberg, P. O.: Importance of secondary sources in the atmospheric budgets of formic and acetic acids, Atmos. Chem. Phys., 11, 1989-2013, https://doi.org/10.5194/acp-11-1989-2011, 2011.

Priestley, M., le Breton, M., Bannan, T. J., Worrall, S. D., Bacak, A., Smedley, A. R. D., Reyes-Villegas, E., Mehra, A., Allan, J., Webb, A. R., Shallcross, D. E., Coe, H., and Percival, C. J.: Observations of organic and inorganic chlorinated compounds and their contribution to chlorine radical concentrations in an urban environment in northern Europe during the wintertime, Atmos. Chem. Phys., 18, 13481-13493, https://doi.org/10.5194/acp-1813481-2018, 2018.

Sanchez, J., Tanner, D. J., Chen, D., Huey, L. G., and Ng, N. L.: A new technique for the direct detection of $\mathrm{HO}_{2}$ radicals using bromide chemical ionization mass spectrometry $(\mathrm{Br}-$ CIMS): initial characterization, Atmos. Meas. Tech., 9, 38513861, https://doi.org/10.5194/amt-9-3851-2016, 2016.

Skalny, J. D., Horvath, G., and Mason, N. L.: Mass spectrometric analysis of small negative ions $(\mathrm{e} / \mathrm{m}<100)$ produced by Trichel pulse negative corona discharge fed by ozonised air, J. Optoelectron. Adv. M., 9, 887-893, 2007. 
Slusher, D. L., Huey, L. G., Tanner, D. J., Flocke, F. M., and Roberts, J. M.: A thermal dissociation-chemical ionization mass spectrometry(TD-CIMS) technique for the simultaneous measurement of peroxyacyl nitrates and dinitrogen pentoxide, J. Geophys. Res.-Atmos., 109, D19315, https://doi.org/10.1029/2004JD004670, 2004.

Souza, S. R. and Carvalho, L. R. F.: Seasonality influence in the distribution of formic and acetic acids in the urban atmosphere of Sao Paulo City, Brazil, J. Brazil. Chem. Soc., 12, 755-762, 2001.

Thornton, J. A., Kercher, J. P., Riedel, T. P., Wagner, N. L., Cozic, J., Holloway, J. S., Dube, W. P., Wolfe, G. M., Quinn, P. K., Middlebrook, A. M., Alexander, B., and Brown, S. S.: A large atomic chlorine source inferred from midcontinental reactive nitrogen chemistry, Nature, 464, 271-274, https://doi.org/10.1038/nature08905, 2010.

Veres, P., Roberts, J. M., Warneke, C., Welsh-Bon, D., Zahniser, M., Herndon, S., Fall, R., and de Gouw, J.: Development of negative-ion proton-transfer chemical-ionization mass spectrometry (NI-PT-CIMS) for the measurement of gas-phase organic acids in the atmosphere, Int. J. Mass Spectrom., 274, 48-55, https://doi.org/10.1016/j.ijms.2008.04.032, 2008.

Veres, P., Gilman, J. B., Roberts, J. M., Kuster, W. C., Warneke, C., Burling, I. R., and de Gouw, J.: Development and validation of a portable gas phase standard generation and calibration system for volatile organic compounds, Atmos. Meas. Tech., 3, 683691, https://doi.org/10.5194/amt-3-683-2010, 2010.
Veres, P. R., Neuman, J. A., Bertram, T. H., Assaf, E., Wolfe, G. M., Williamson, C. J., Weinzierl, B., Tilmes, S., Thompson, C. R., Thames, A. B., Schroder, J. C., Saiz-Lopez, A., Rollins, A. W., Roberts, J. M., Price, D., Peischl, J., Nault, B. A., Moller, K. H., Miller, D. O., Meinardi, S., Li, Q. Y., Lamarque, J. F., Kupc, A., Kjaergaard, H. G., Kinnison, D., Jimenez, J. L., Jernigan, C. M., Hornbrook, R. S., Hills, A., Dollner, M., Day, D. A., Cuevas, C. A., Campuzano-Jost, P., Burkholder, J., Bui, T. P., Brune, W. H., Brown, S. S., Brock, C. A., Bourgeois, I., Blake, D. R., Apel, E. C., and Ryerson, T. B.: Global airborne sampling reveals a previously unobserved dimethyl sulfide oxidation mechanism in the marine atmosphere, P. Natl. Acad. Sci. USA, 117, 4505-4510, 2020.

Wang, X. F., Wang, T., Xue, L. K., Nie, W., Xu, Z., Poon, S. C. N., and Wang, W. X.: Peroxyacetyl nitrate measurements by thermal dissociation-chemical ionization mass spectrometry in an urban environment: performance and characterizations, Front. Env. Sci. Eng., 11, 3, https://doi.org/10.1007/s11783-017-0925-7, 2017.

Warneck, P. and Zerbach, T.: Synthesis of peroxyacetyl nitrate in air by acetone photolysis, Environ. Sci. Technol., 26, 74-79, 1992. 